\title{
Animales silvestres y derecho procesal constitucional
}

Wild animals and constitutional procedural law

Animais selvagens e direito processual constitucional

\section{Milton Dubán Monsalve Mantilla'}

Recibido: 24 de mayo de 2021

Aprobado: 20 de octubre de 2021

Publicado: 24 de diciembre de 2021

Cómo citar este artículo:

Milton Dubán Monsalve Mantilla. Animales silvestres y derecho procesal constitucional.

DIXI, vol. 24, $n^{\circ}$. 1, enero-junio 2022, 1-24.

DOI: https://doi.org/10.16925/2357-5891.2022.01.03

Artículo de investigación. https://doi.org/10.16925/2357-5891.2022.01.03

1 Doctorando en Derecho, Economía y Empresa de la Universidad de Girona, España. Abogado de la Universidad Industrial de Santander. Especialista en Derecho Administrativo de la Universidad Externado de Colombia. Magíster en Derecho Universidad Externado de Colombia. Docente universitario. Servidor público por concurso de méritos.

ORCID: https://orcid.org/0000-0003-3417-7325

CVLAC: https://scienti.minciencias.gov.co/cvlac/visualizador/generarCurriculoCv.do? cod_rh $=0000018173$ 


\title{
Resumen
}

Introducción: en Colombia el derecho procesal constitucional y las acciones contempladas en la Constitución Política, especialmente el habeas corpus, la acción popular y la acción de tutela, tienen una marcada destinación antropocéntrica, lo cual hace inoperante su utilización en favor de las demás especies animales.

Metodología: a través de un análisis documental descriptivo, se indaga por la naturaleza del derecho procesal constitucional y su incidencia en la protección de animales silvestres en Colombia, revisando jurisprudencia y acudiendo al análisis de fuentes.

Hallazgos: si bien se ha avanzado en leyes que impactan la protección animal, la protección y conservación de especies animales, vía jurisdiccional, será nugatoria mientras no se creen nuevas acciones destinadas exclusivamente en favor de los animales no humanos (reconocer una nueva especialidad como el derecho animal), o mientras se premie el interés general del animal sobre el formalismo propio del derecho procesal constitucional.

Conclusiones: la Corte Constitucional, en Sentencia de Unificación 016 de enero de 2020, determinó que el habeas corpus solo es procedente para la protección del derecho fundamental a la libertad de las personas y no es posible su utilización en el caso de los animales no humanos. La protección y conservación de los animales constituye un derecho colectivo de conformidad con los artículos 8, 79, 80, 88, 95-8 de la Constitución Política para lo cual procede acción popular. No obstante, la dependencia del "derecho animal" de otras especialidades del derecho, en el caso preciso del derecho "procesal constitucional", ha ocasionado obstáculos en la protección real y efectiva de las especies animales silvestres en Colombia.

Palabras clave: acción popular, animales silvestres, derecho animal, habeas corpus.

\begin{abstract}
Introduction: In Colombia, constitutional procedural law and the actions contemplated in the Political Constitution, especially habeas corpus, the popular action and the tutela action, have a marked anthropocentric destination, which makes their use in favor of other animal species inoperative.

Methodology: Through a descriptive documentary analysis, the nature of constitutional procedural law and its incidence on the protection of wild animals in Colombia is investigated, reviewing jurisprudence and analyzing sources.
\end{abstract}

Findings: Although progress has been made in laws that impact animal protection, the protection and conservation of animal species, via jurisdictional means, will be nugatory as long as new actions are not created exclusively in favor of non-human animals (recognizing a new specialty such as animal law), or as long as the general interest of the animal is rewarded over the formalism of constitutional procedural law.

Conclusions: The Constitutional Court, in Unification Ruling 016 of January 2020, determined that habeas corpus is only appropriate for the protection of the fundamental right to freedom of persons, and it is not possible to use it in the case of non-human animals. The protection and conservation of animals constitutes a collective right in accordance with articles 8, 79, 80, 88, 95-8 of the Political Constitution for which a popular action is appropriate. However, the dependence of "animal law" on other specialties of law, in the precise case of "constitutional procedural" law, has caused obstacles in the real and effective protection of wild animal species in Colombia.

Keywords: Popular action, wild animals, animal law, habeas corpus. 


\section{Resumo}

Introdução: Na Colômbia, a lei processual constitucional e as ações contempladas na Constituição Política, especialmente o habeas corpus, a ação popular e a ação tutelar, têm um marcado enfoque antropocêntrico, o que torna inoperante seu uso em favor de outras espécies animais.

Metodologia: Através de uma análise documental descritiva, investigamos a natureza do direito processual constitucional e seu impacto na proteção dos animais selvagens na Colômbia, revisando a jurisprudência e analisando as fontes.

Conclusões: Embora tenha havido progresso nas leis que têm um impacto na proteção dos animais, a proteção e conservação das espécies animais, através dos tribunais, serão insignificantes até que novas ações sejam criadas exclusivamente para animais não humanos (reconhecendo uma nova especialidade como a lei animal), ou até que o interesse geral do animal seja recompensado com o formalismo da lei processual constitucional. Conclusões: A Corte Constitucional, na Acórdão de Unificação 016 de janeiro de 2020, determinou que o habeas corpus só é apropriado para a proteção do direito fundamental à liberdade das pessoas, e não é possível utilizá-lo no caso de animais não-humanos. A proteção e conservação dos animais constitui um direito coletivo de acordo com os artigos 8, 79, 80, 88, 95-8 da Constituição Política, para o qual uma ação popular é apropriada. Entretanto, a dependência da "lei animal" de outras especialidades da lei, no caso específico da lei "processual constitucional", tem causado obstáculos para a proteção real e efetiva das espécies animais silvestres na Colômbia.

Palabras-chave: Ação popular, animais selvagens, lei animal, habeas corpus.

\section{INTRODUCCIÓN. CONTEXTO DE PROTECCIÓN JURÍDICA DE ANIMALES SILVESTRES EN COLOMBIA}

La Constitución de Colombia de 1991 ha sido considerada por muchos como una constitución ecológica. Se ha dicho que el tema ambiental se constitucionalizó, pues al haberse hecho mención directa al ambiente en las normas de mayor rango obliga, además, a considerarlo como interés jurídico merecedor de la mayor protección, al que ya no se puede considerar, en ninguna circunstancia, como periférico ni secundario'.

Sin perjuicio de lo antes dicho, en ninguno de los artículos de la Constitución se nombra directamente la protección y defensa de los animales. El artículo 79, aunque de manera indirecta, se refiere a ello al señalar en su inciso segundo que "es deber del Estado proteger la diversidad e integridad del ambiente, conservar las áreas de especial importancia ecológica y fomentar la educación para el logro de estos fines". Los

1 Óscar Darío Amaya Navas. LA CONSTITUCIÓN ECOLÓGICA DE COLOMBIA. Editorial Universidad Externado de Colombia. (2010) 
artículos 8 y 95, numeral 8, disponen como principio constitucional y como deber de los colombianos y del Estado proteger las riquezas naturales y proteger el ambiente.

En la década de 1970, en Colombia se expidió el Código Nacional de los Recursos Naturales Renovables y de Protección al Medio Ambiente. Allí se dejó dicho que la preservación y el manejo de los recursos naturales renovables son de utilidad pública e interés social y, además, que la administración tiene facultades para, entre otras cosas, clasificar las especies que requieran un tipo especial de manejo y velar por la adecuada conservación, fomento y restauración de la fauna silvestre?2.

Adicional a esto, el artículo 3 del Código señala que dentro de la comprensión de protección del ambiente se entiende inmersa la fauna en todas sus expresiones. En cuanto a la fauna silvestre, posteriormente se expidió el Decreto 1608 de 1978, en el que se reiteró que "las actividades de preservación y manejo de la fauna silvestre son de utilidad pública e interés social", normatividad que se encuentra compilada en el Decreto Único Reglamentario del Sector Ambiente 1076 de 2015.

Hacia 1989 se expidió la Ley 84, la cual ha sido reformada por la Ley 1774 de 2016 (Ley de Maltrato Animal). En tal estatuto se establece como uno de sus objetivos desarrollar medidas efectivas para la preservación de la fauna silvestre.

Con el cambio constitucional de 1991, se sancionó la Ley 99 de 1993, que señala los principios que rigen la política ambiental colombiana y dispone que la biodiversidad del país, por ser patrimonio nacional y de interés de la humanidad, debe ser protegida prioritariamente y aprovechada en forma sostenible ${ }^{3}$. Además, establece que corresponde al Ministerio del Medio Ambiente adoptar las medidas necesarias para asegurar la protección de las especies de fauna y flora silvestres, y tomar las previsiones que sean del caso para defender las especies en vías de extinción o en peligro de estarlo 4 .

En el año 2013, se prohibió la tenencia y utilización de los animales silvestres en espectáculos circenses, obligación que se empezaría a cumplir a partir de $2015^{5}$,

2 Presidencia de la República. Decreto Ley 2811 de 1974. Por el cual se dicta el Código Nacional de Recursos Naturales Renovables y de Protección al Medio Ambiente. Diciembre 18 de 2019. Do N. ${ }^{\circ} 34.243$.

3 Congreso de la República. Ley 99 de 1993. Por la cual se crea el Ministerio del Medio Ambiente, se reordena el Sector Público encargado de la gestión y conservación del medio ambiente y los recursos naturales renovables, se organiza el Sistema Nacional Ambiental, SINA, y se dictan otras disposiciones. Diciembre 22 de 1993. Do N. ${ }^{\circ} 41.146$.

4 Ibidem. Numeral 23. Artículo 5.

5 Congreso de la República. Ley 1638 de 2013. Por medio de la cual se prohíbe el uso de animales silvestres, ya sean nativos o exóticos, en circos fijos e itinerantes. Junio 27 de 2013. DO N. ${ }^{\circ} 48.834$. 
cuando empieza una nueva etapa en la reconfiguración del entendimiento de protección frente a los animales.

Por su parte, con la expedición de la Ley de Maltrato Animal se creó un nuevo tipo penal denominado "de los delitos contra los animales". Allí se establecen penas de prisión de doce a 36 meses para aquella persona que maltrate a un animal domesticado, amansado, silvestre vertebrado o exótico vertebrado, causándole la muerte o lesiones que menoscaben gravemente su salud o integridad física, y se asignó el conocimiento de dichos delitos a los Juzgados Penales Municipales.

Así mismo, se reformó la Ley 84 de 1989 (Estatuto Animal) en el sentido de sancionar con multas de cinco a sesenta salarios mínimos legales mensuales vigentes los actos dañinos y de crueldad contra los animales. Y se asignó a los alcaldes municipales y a los inspectores de policía la función de adelantar el procedimiento administrativo sancionatorio a que ello dé lugar, lo cual implica una nueva obligación de estas autoridades administrativas y, por supuesto, redunda en un nuevo entendimiento de la relación administración-animales.

Dicha norma trajo consigo el señalamiento de ciertos "principios" que redundan en favor de los animales. La relación humano-animal debe basarse en el respeto, la solidaridad, la compasión, la ética, la justicia, el cuidado, la prevención del sufrimiento, la erradicación del cautiverio y el abandono, así como en la prevención de cualquier forma de abuso, maltrato, violencia y trato cruel. En cuanto al "bienestar animal", el responsable o tenedor de ellos debe garantizar: 1) que no sufran hambre ni sed; 2) que no sufran injustificadamente malestar físico ni dolor; 3) que no les sean provocadas enfermedades por negligencia o descuido; 4) que no sean sometidos a condiciones de miedo ni estrés; 5) que puedan manifestar su comportamiento natural. Todo lo anterior, bajo el principio de solidaridad social que dispone la obligación del Estado, la sociedad y sus miembros de asistir y proteger a los animales frente a situaciones que atenten contra su integridad y su vida ${ }^{6}$.

Para el mismo año, el Congreso de la República expidió la Ley 1801 de 2016 (Código Nacional de Policía y Convivencia), que en cierta forma complementó la Ley 1774 de 2016, el título XIII "De la relación con los animales" y el capítulo I "Del respeto y cuidado de los animales". Es así como, a partir del artículo 116, se establecieron disposiciones que redundan en la regulación de una serie de comportamientos que atañen a los animales. Valga resaltar que, por ejemplo, dispone la obligación de los municipios de contar con albergues para animales en condición de abandono.

6 Congreso de la República. Ley 1774 de 2016. Por medio de la cual se modifican el Código Civil, la Ley 84 de 1989, el Código Penal, el Código de Procedimiento Penal y se dictan otras disposiciones. Enero 6 de 2016. Do N. ${ }^{\circ} 39.120$. 
Tanto la Ley 1774 de 2016, como la Ley 1801 de 2016 representan un avance para la protección, la conservación y el reconocimiento de los animales como "sujetos de derechos"7, pero sin que ello signifique que se ha abandonado la visión antropocéntrica del derecho en nuestro Estado8.

Frente al tema objeto de estudio, en el título Ix "Del ambiente", capítulo ॥ "Recurso hídrico, fauna, flora y aire", en su artículo 101 se tipificaron comportamientos que afectan la fauna y flora silvestre. Además, se estableció un catálogo de sanciones que van desde la amonestación, la participación en programas comunitarios o en actividades pedagógicas de convivencia y la suspensión temporal de actividad, hasta la multa general tipo 4 por comportamientos que afectan la fauna silvestre.

Algunos comportamientos que afectan la fauna silvestre son los siguientes: colectar, aprovechar, mantener, tener, transportar, introducir, comercializar, o poseer especies de fauna silvestre (viva o muerta) o sus partes, sin la respectiva autorización ambiental, contaminar o envenenar recursos fáunicos, forestales o hidrobiológicos, experimentar, alterar, mutilar, manipular las especies silvestres sin el permiso de autoridad ambiental competente, violar los reglamentos establecidos para los períodos de veda en materia de caza y pesca, tener animales silvestres en calidad de mascotas ${ }^{9}$.

En vista de lo anterior, puede concluirse que existe una reglamentación extensa en torno a la protección de especies animales silvestres, incluso dicha reglamentación comenzó antes de la Constitución Política de 1991. Allí se vislumbran distintas medidas de carácter administrativo tendientes a su protección; no obstante, las disposiciones con incidencia jurisdiccional merecen especial análisis.

En ese contexto, revisaremos la relación que existe entre el derecho procesal constitucional y la protección de la fauna silvestre, haciendo énfasis en dos mecanismos consagrados en la Constitución: el habeas corpus y la acción popular, mediados por la acción de tutela.

7 Luz Marcela Pérez Arias y Milton Dubán Monsalve Mantilla. Maltrato animal en Colombia: protección penal y contravencional en favor de los animales. DIXI 32. 2020. Pág. 1-16. Disponible en: https://doi.org/10.16925/2357-5891.2020.02.07

8 En el escrito "Maltrato animal en Colombia: protección penal y contravencional en favor de los animales", buscamos puntos de intersección entre el derecho penal y el régimen contravencional, a fin de aclarar las diferencias que existen y los objetivos y propósitos de cada norma a la hora de reprochar las conductas que entrañan maltrato en contra de los animales.

9 Congreso de la República. Ley 1801 de 2016. Por la cual se expide el Código Nacional de Seguridad y Convivencia Ciudadana. Julio 29 de 2016. Do N. ${ }^{\circ} 49.949$. 


\section{Metodología}

El presente trabajo está circunscrito a una revisión documental, y con ese fin se realizó una exploración de antecedentes que determinaron el objetivo de lo propuesto. En este orden, se revisó el texto de la Constitución Política de Colombia y las fuentes del derecho procesal constitucional, y se analizó la Sentencia de Unificación 016 de 2020 de la Corte Constitucional y la sentencia con radicado 25000-23-24-000-201100227-01 (AP) del Consejo de Estado, Sala Contencioso Administrativa, Sección Tercera del 26 de noviembre de 2013, acudiendo también a otras decisiones judiciales y a la doctrina que aborda el objeto de estudio.

El análisis de la información recopilada se llevó a cabo dando prioridad a las normas que tratan sobre la materia, con una finalidad descriptiva; después, se contrastó toda la información para sentar una posición sobre el tema.

\section{ESQUEMA DE RESOLUCIÓN DEL TEMA PROPUESTO}

Se pretende: 1) exponer la relación del derecho procesal constitucional y la protección de la fauna silvestre; 1.2) analizar la procedencia del habeas corpus para la protección de animales silvestres; 1.3) examinar la acción popular y su incidencia en la protección de fauna silvestre; y 2) establecer unas breves conclusiones.

\section{ANIMALES SILVESTRES Y DERECHO PROCESAL CONSTITUCIONAL}

Colombia, en 1991, hace tránsito a un nuevo orden constitucional. La Constitución, además de traer consigo un componente dogmático en el que se constitucionalizaron varios principios, valores y derechos, trae un componente orgánico que demarca debidamente la organización del Estado, del territorio y de sus instituciones. No obstante, como novedad se tiene que adoptó una serie de acciones conducentes a la protección de los derechos allí consagrados.

Con ello, se empieza a expandir el derecho procesal constitucional, cuyo objeto es estudiar y dar relevancia a los aspectos procesales propios de las acciones y los procesos constitucionales consagrados en la Carta magna. Además, en 1991 nace la Corte Constitucional Colombiana, la cual encuentra su desarrollo normativo en los 
artículos 239 a 245, en la Ley 270 de 1996 Estatutaria de la Administración de Justicia, artículos 43-49, y en algunos actos reglamentarios de este tribunal.

Es importante mencionar que ha habido resistencia en el sentido de entender la disciplina del derecho procesal constitucional como un área autónoma. Incluso, en palabras del profesor Manuel Fernando Quinche, "a los constitucionalistas tradicionales no les gusta la formulación del derecho procesal constitucional, pues en su opinión, el derecho constitucional es sustantivo y no procesal"10; y resalta que para los procesalistas, "el derecho procesal es uno solo y el derecho procesal constitucional sería una simple variedad de aquel"11. En palabras del autor boliviano Pablo Dermizaky Peredo, el derecho procesal constitucional es probablemente la disciplina jurídica más nueva, pues su contenido, denominación y enseñanza aparecen en la segunda mitad del siglo $x x^{12}$.

Por su parte, el tratadista Quinche aboga por la autonomía del derecho procesal constitucional, explicando que su objeto puede visualizarse según cuatro tesis introducidas a nuestro país: i) la tesis restringida que reduce el estudio del derecho procesal constitucional al estudio de la magistratura y los procesos constitucionales; ii) la tesis intermedia para la cual el objeto de estudio es la jurisdicción constitucional, los procesos constitucionales y la magistratura constitucional; iii) la tesis amplia que considera como objeto el análisis de la jurisdicción constitucional orgánica, de libertad, supranacional y el estudio de las instituciones procesales constitucionales; y iv) la "tesis amplísima" que extiende el objeto de estudio del derecho procesal constitucional incluso al análisis del debido proceso y las garantías judiciales ${ }^{13}$.

De conformidad con lo dicho por Dermizaky, el derecho procesal constitucional tiene una naturaleza de carácter mixto, dado que:

[...] es sustantiva porque comprende lo que Mauro Cappelletti y Héctor Fix-Zamudio denominan la jurisdicción constitucional de la libertad y la jurisdicción constitucional orgánica. La primera relativa a la defensa y protección de los derechos fundamentales de la persona, y la segunda, a la constitución y funcionamiento de los órganos del Estado, todo lo cual

10 Manuel Fernando Quinche Ramírez. DERECHO PROCESAL CONSTITUCIONAL COLOMBIANO. ACCIONES Y PROCESOS. Ediciones Doctrina y Ley. (2015).

11 Ibidem. Pág. 1.

12 Pablo Dermizaky Peredo. El derecho proceso constitucional. REVISTA BOLIVIANA DE DERECHO 4. 2007. Pág. 1-20.

13 Manuel Fernando Quinche Ramírez, supra, nota 11. 
es materia sustantiva y central de la Constitución Política del Estado. Y es adjetiva porque se vale de normas procesales para poner en actividad a la jurisdicción constitucional en defensa y observancia de la Constitución.14

Así las cosas, independientemente de las tesis que se asuman, lo cierto es que en nuestro medio el análisis de las acciones constitucionales hace parte del derecho procesal constitucional.

En ese entendido, encontramos que con la nueva Carta Superior se incorporaron algunas acciones para la defensa de los derechos constitucionales. El habeas corpus, por ejemplo, se encuentra consagrado en el artículo 30 de la Constitución y tiene la doble connotación de ser derecho fundamental y a la vez acción constitucional para la protección del derecho a la libertad. La acción de tutela se encuentra regulada en el artículo 86 de la Carta magna y reglamentada por el Decreto 2591 de 1991. La acción de inconstitucionalidad nació en el siglo XX, primero en cabeza de la Corte Suprema de Justicia y luego fue asignada a la Corte Constitucional según el artículo 241 de la Constitución Política. La acción de cumplimiento tiene sustento en los artículos 2, 40.6 y 87 constitucionales y constituye el mecanismo para que cualquier persona haga efectivo el cumplimiento de una ley o un acto administrativo, con desarrollo en la Ley 393 de 1997. También, encontramos la acción popular y la acción de grupo, consagradas en el artículo 88 de la Constitución y desarrolladas por la Ley 472 de 1998, con algunos elementos determinantes dispuestos en la Ley 1437 de 2011, actual Código de Procedimiento Administrativo y lo Contencioso Administrativo.

Si bien podríamos hacer un análisis de cada una de estas acciones y su repercusión en la protección de la fauna silvestre, centraremos nuestra atención en el estudio de algunas de ellas: el habeas corpus y la acción popular, mediadas por la acción de tutela, con referencia a dos casos muy controvertidos.

\section{LA PROTECCIÓN DE LA FAUNA SILVESTRE Y HABEAS CORPUS: CASO DEL OSO 'CHUCHO'}

El habeas corpus en Colombia está consagrado en el artículo 30 constitucional. Tiene una doble connotación, como derecho fundamental positivizado y como acción constitucional para la protección del derecho a la libertad, el cual debe resolverse al término máximo de 36 horas.

14 Pablo Dermizaky Peredo, supra, nota 13. 
En ese contexto, se ha dicho que al estar sustentada la pretensión del proceso de habeas corpus en la protección de un derecho constitucional, busca la satisfacción de una pretensión de amparo originada en una privación ilegal de la libertad ${ }^{15}$. Con la Ley 1095 de 2006, se reglamentó el artículo 30 constitucional, y se dejó dicho que el habeas corpus no se suspenderá ni en los Estados de excepción y que puede ser interpuesto por la misma persona o por terceros.

En enero de 2020, la máxima autoridad de la jurisdicción constitucional coIombiana profirió la Sentencia de Unificación 016 del 23 de enero de 2020, en la que se analizaron varias decisiones en el interior de la jurisdicción ordinaria y de las Salas de Decisión de la Corte Suprema de Justicia, entre ellas una decisión proferida por la Sala de Casación Civil, en la que se le había concedido un habeas corpus a un oso andino llamado 'Chucho'.

Según se narra en dicha providencia, 'Chucho' es un oso andino, de 22 a 24 años, nacido en el departamento de Nariño, que fue trasladado primero a la Reserva Forestal Protectora del Río Blanco en Manizales y luego a la Fundación Botánica y Zoológica de Barranquilla (Fundazoo), a partir de junio de 2017. Frente a tal suceso, un ciudadano interpuso en esa misma fecha un habeas corpus por considerar que dichos traslados, y especialmente el realizado a la ciudad de Barranquilla, sometían al animal a condiciones inapropiadas de vida y de cautiverio.

La acción fue fallada desfavorablemente en primera instancia por parte del Tribunal Superior de Manizales, en el entendido de que el habeas corpus no procede al ser una acción constitucional que protege los derechos fundamentales y estos no recaen en los animales, sino en las personas.

En segunda instancia, en un fallo trascendental, la Sala de Casación Civil de la Corte Suprema de Justicia revocó la decisión anterior y concedió el habeas corpus al oso 'Chucho'. En consecuencia, este tribunal ordenó a Fundazoo, a Corpocaldas, a Aguas de Manizales, a la Unidad Administrativa Especial del Sistema de Parques Nacionales Naturales y al Ministerio del Ambiente acordar y disponer el traslado del oso 'Chucho' a un lugar que se adecuara a sus necesidades y donde el oso pudiese permanecer en estado de semicautiverio. La Sala de Casación Civil de la Corte Suprema de Justicia consideró que, aunque en principio el habeas corpus fue diseñado para garantizar la libertad de las personas, ello no excluye su utilización para exigir 
la protección de los animales como seres sintientes y como "sujetos de derechos"16, en consonancia con la reglamentación actual sobre la materia.

Ahora bien, un fenómeno que se da como resultado de nuestro sistema procesal constitucional es que las decisiones judiciales, aunque sean de segunda instancia, pueden ser objeto de "revisión" y "reproche" si contra ellas se interpone la acción de tutela ${ }^{17}$ alegando vulneración de algún derecho fundamental. En ese sentido, Fundazoo impetró acción de tutela contra la sentencia de la Sala de Casación Civil de la Corte Suprema de Justicia, la cual fue evaluada en primera instancia por la Sala Laboral y en segunda instancia por la Sala Penal de la misma Corte Suprema de Justicia. Ambas Salas concedieron el amparo de tutela y, por consiguiente, dejaron sin efecto las decisiones adoptadas en el marco del habeas corpus por la Sala de Casación Civil de la Corte Suprema de Justicia.

Es así como la Corte Constitucional, haciendo uso del mecanismo de revisión de los fallos de tutela preceptuado en el artículo 241.9 de la Constitución, que le permite "revisar, en la forma que determine la ley, las decisiones judiciales relacionadas con la acción de tutela de los derechos constitucionales", asumió la revisión de los fallos de tutela proferidos por la Sala de Casación Laboral y Penal de la Corte Suprema de Justicia y entró a revisar de fondo la situación planteada por el habeas corpus en favor del oso 'Chucho'.

La Corte Constitucional dictó Sentencia de Unificación 016 del 23 de enero de 2020. Es importante mencionar que, en el esquema constitucional colombiano, las sentencias de unificación son providencias de la Corte Constitucional, en virtud del inciso segundo del artículo 86 de la Constitución Nacional. El artículo 33 del Decreto 2591 de 1991 establece que no existe una mención expresa a que la revisión se haga con el objeto de unificar jurisprudencia.

En palabras del autor Juan Carlos Guayacán, este propósito puede intuirse a partir de dos circunstancias. La primera es que el referido artículo 33, al establecer la posibilidad de insistencia en tal revisión eventual, indica que los organismos legitimados para presentar esta insistencia pueden invocar la necesidad de precisar el alcance de un derecho. La segunda es que lo expresado por la Corte Constitucional cuando examinó la exequibilidad de la revisión eventual, en la que manifestó que la labor en materia de tutela es, entre otras, de consolidación de la jurisprudencia, además se considera una prerrogativa exclusiva de la Corte Constitucional, sin ninguna iniciativa

16 En Sentencia SU-016 de 2020, en los antecedentes se citan las razones de la Sala de Casación Civil de la Corte Suprema de Justicia en decisión que sí concedió el habeas corpus al oso 'Chucho'.

17 La acción de tutela se encuentra consagrada en el artículo 86 de la Constitución Política para la protección de los derechos fundamentales. 
por parte del justiciable ${ }^{18}$. En ese entendido, la Corte Constitucional escogió los fallos de tutela antes referenciados para analizar el habeas corpus del oso 'Chucho' y su procedencia.

Como aspecto sobresaliente, se tiene que la Magistratura Constitucional en esta sentencia de unificación confirmó los fallos de tutela proferidos por la Sala de Casación Laboral en primera instancia y por la Sala de Casación Penal de la Corte Suprema de Justicia en segunda instancia; por tanto, consideró que al conceder el habeas corpus al oso 'Chucho', efectivamente se había vulnerado el debido proceso a Fundazoo, pues la Sala de Casación Civil de la Corte Suprema de Justicia había cometido un error de tipo procedimental absoluto que llevó a la vulneración del debido proceso de la fundación, sin entrar a evaluar el presunto error en el aspecto fáctico y sustantivo.

La Corte Constitucional consideró que se configuró el defecto procedimental absoluto ${ }^{19}$, pues en su criterio el habeas corpus no es el instrumento procesal adecuado. La Corte fue enfática en señalar que este es un mecanismo para la protección de la libertad de las personas y no es aplicable a los animales. A su vez, argumentó que ni siquiera se pretendía el regreso del oso a su estado natural y que su avanzada edad y su forma de vida en cautiverio se lo impediría. En suma, para la Corte, lo que se buscó en el aparato judicial fue garantizar condiciones de bienestar del animal, pero ni la naturaleza del habeas corpus (que es defender la libertad de las personas) ni su estructura procesal están dadas para suscitar una controversia como la propuesta frente al oso 'Chucho'.

18 Juan Carlos Guayacán. La selección de sentencias para la unificación de la jurisprudencia. Tres historias paralelas entre la Corte Constitucional, el Consejo de Estado y la Sala de Casación Civil de la Corte Suprema de Justicia. REVISTA DE DERECHO PRIVADO 19. Diciembre de 2020. Pág. 57-79.

19 En cuanto al defecto procedimental, la Corte ha dicho que: (a) el defecto procedimental absoluto ocurre cuando "se aparta por completo del procedimiento establecido legalmente para el trámite de un asunto específico, ya sea porque: i) se ciñe a un trámite completamente ajeno al pertinente -desvía el cauce del asunto- o ii) omite etapas sustanciales del procedimiento establecido legalmente, afectando el derecho de defensa y contradicción de una de las partes del proceso. (b) El defecto procedimental por exceso de ritual manifiesto, ocurre cuando la autoridad judicial [...] un funcionario utiliza o concibe los procedimientos como un obstáculo para la eficacia del derecho sustancial y, por esta vía, sus actuaciones devienen en una denegación de justicia". Es decir, el funcionario judicial incurre en esta causal cuando "(i) no tiene presente que el derecho procesal es un medio para la realización efectiva de los derechos de los ciudadanos, (ii) renuncia conscientemente a la verdad jurídica objetiva pese a los hechos probados en el caso concreto, (iii) porque aplica rigurosamente el derecho procesal, (iv) pese a que dicha actuación devenga en el desconocimiento de derechos fundamentales". Ver Sentencia T-367 de 2018, se cita Sentencia T-327 de 2011 (M.P. Jorge Ignacio Pretelt Chaljub), reiterada en la Sentencia T-352 de 2012 (M.P. Jorge Ignacio Pretelt Chaljub) y en la Sentencia T-398 de 2017 (M.P. Cristina Pardo Schlesinger). 
Así puntualiza la Corte: "A juicio de la Sala, esta inconsistencia entre la naturaleza, el objeto y la estructura del habeas corpus y la problemática planteada en el proceso judicial configura un defecto procedimental absoluto"20. Y termina señalando que "el defecto procedimental absoluto se produce cuando la autoridad judicial actúa al margen de los procedimientos establecidos por el legislador, tanto desde el punto de vista sustantivo, como desde el punto de vista formal y procesal"21.

En cuanto al defecto fáctico y el defecto sustantivo, la Corte ni siquiera se pronunció, pues manifestó que, por sustracción de materia, al no ser procedente la acción, no había siquiera lugar a estudiar el soporte fáctico y jurídico de las decisiones. Veamos:

Habiéndose configurado el defecto procedimental absoluto, no hay lugar al análisis del defecto fáctico ni del defecto sustantivo alegados por el accionante, ya que al haberse descartado la viabilidad de la acción de habeas corpus, carece de sentido entrar a determinar si la decisión adoptada en el marco de una acción que de por sí era improcedente, contó con el soporte fáctico y probatorio debido, y si se ajustó a la normatividad constitucional y legal. De esta suerte, por sustracción de materia la Sala omite el análisis del vicio alegado. ${ }^{22}$

Por lo demás, la Corte se limitó a expresar que se han dado varias normas tendientes a la protección de los animales y, con ello, un avance progresivo en su denominación como "seres sintientes", pero esto no implica la posibilidad de hacer uso del habeas corpus. Fue enfática en señalar que se ha avanzado en la configuración de la prohibición del maltrato animal y de los mecanismos para hacer efectivas esas prohibiciones, así como en los debates alrededor del confinamiento y el cautiverio de los animales silvestres, pero bajo los estándares del bienestar animal. Cerró diciendo que frente a la situación bien pudo acudirse directamente a solicitar la intervención de las autoridades ambientales o interponer una acción popular para canalizar adecuadamente las controversias ${ }^{23}$.

20 Corte Constitucional de Colombia. SENTENCIA SU-016 DE 2020. (M.P. Luis Guillermo Guerrero Pérez; enero 23 de 2020).

21 Ibidem.

22 Ibidem.

23 Ibidem. 
La decisión de la Corte puede circunscribirse al contexto de las apreciaciones del profesor Diego López Medina ${ }^{24}$, para quien la relación entre los animales humanos y no humanos puede sintetizarse en cuatro momentos: 1) soberanía humana sobre el reino animal; 2) paradigma bienestarista; 3) paradigma ambientalista; y 4) paradigma de los derechos de los animales. En cuanto a la soberanía humana sobre el reino animal, o antropocentrismo, dice el autor que los animales son considerados como objetos naturales, que pueden ser apropiados y dominados por el hombre. Por tanto, se pueden instrumentalizar en favor de los intereses humanos.

Respecto al paradigma bienestarista explica que, aunque los animales son considerados como objetos naturales e instrumentalizables, se pregona por evitar su maltrato y su sufrimiento, de tal forma que se aprovechen, pero de una forma mínimamente humanitaria. Consideramos que aquí se encontró circunscrita la decisión de la Corte Constitucional, desde el punto de vista teórico, sin que se tomaran verdaderas medidas de protección en torno al oso 'Chucho'.

Frente al paradigma ambientalista, señala que acá los individuos de la especie, sea animal humana o no humana, no tienen mayor peso moral, pues lo más importante es la preservación de la biodiversidad de las especies, la funcionalidad del medio ambiente y proteger a los individuos del ecosistema para el mantenimiento de su estabilidad, diversidad y preservación.

Por último, frente al paradigma más moderno, el de los derechos de los animales, dice que se considera que:

[...] los animales tienen un interés directo en su propia vida y en su bienestar. Llevar las vidas más complejas y satisfactorias-según las habilidades y restricciones de su propia especie- constituye una expectativa razonable que se consolida en derechos individuales. Este máximo de derecho, sin embargo, puede irse construyendo incrementalmente, empezando por los más básicos y terminando en una completa reconstrucción conceptual de los animales como sujetos de derecho. ${ }^{25}$

Del paradigma anterior, encontramos apoyo en doctrinas filosóficas como las de la teórica norteamericana Martha Nussbaum, quien es tajante en prescribir lo siguiente:

24 Diego Lopéz Medina. EL CAMBIO DogmÁtICo-JURídICo como RESPUESTA AL CAMBIO SoCIAL: LA LABOR DEL CONSEJO DE ESTADO Y DE LA CORTE CONSTITUCIONAL EN LA RECONSIDERACIÓN DEL ESTATUTO JURÍDICO DE LOS ANIMALES EN COLOMBIA. Editorial Universidad Externado. (2015).

25 Ibidem. Pág. 533. 
El territorio de la justicia es el territorio de los derechos básicos. Cuando digo que el maltrato animal es injusto, quiero decir no solo que está mal de nuestra parte que los tratemos así, sino que ellos tienen un derecho de índole moral a no ser tratados de ese modo. Es injusto para ellos. ${ }^{26}$

Desde nuestra perspectiva, la Corte Constitucional premió el formalismo procedimental sobre la discusión fáctica del oso 'Chucho', sin conceder una respuesta de fondo a la situación del mencionado animal. Incluso, se hubiese esperado un pronunciamiento de la Corte en relación con los principios de bienestar animal consagrados en la Ley 1774 de 2016, pues de nada sirve que estén descritos en la norma si el ordenamiento jurídico no dispone de acciones jurisdiccionales precisas para su activación.

Es importante hacer notar que en la decisión se dio un salvamento de voto bastante destacable por parte de la magistrada Diana Fajardo Rivera, quien señaló que los animales sí son titulares de derechos, pues tienen intereses jurídicamente relevantes que deben ser protegidos por el ordenamiento jurídico, toda vez que ya existe una construcción jurisprudencial que parte de la base de entender a los animales como seres sintientes con un valor intrínseco. A saber, los mandatos de bienestar animal que se desprenden de la categoría de "sintiencia" de la Ley 1774 de 2016; los desarrollos jurisprudenciales dados en otros países; las obligaciones de conservación del medio ambiente, que se expresan en varios instrumentos internacionales; y todas las aportaciones teóricas, filosóficas y científicas que dan cuenta de dicha posibilidad. Además, manifestó que conceder la libertad al oso 'Chucho' en ese caso particular era un asunto necesario y de justicia ${ }^{27}$.

Para la magistrada Fajardo, los animales sí son sujetos de derecho y en especial del derecho a la libertad, máxime cuando se trata de un animal silvestre ${ }^{28}$. Luego, la discusión no debió centrarse de forma simple en el formalismo del habeas corpus, sino en cuál sería entonces el mecanismo procesal para la protección de la libertad del animal.

La Corte Constitucional consideró, refiriéndose a la Sala de Casación Civil de la Corte Suprema de Justicia (la cual sí había concedido el habeas corpus), que había cometido un yerro, pues: "[...] falló porque canalizó el debate propuesto por el

26 Martha Nussbaum. LAS FRONTERAS DE LA JUSTICIA: CONSIDERACIONES SOBRE LA EXCLUSıón. Paidós. (2006).

27 Corte Constitucional de Colombia. SENTENCIA SU-016 DE 2020. (M.P. Luis Guillermo Guerrero Pérez; enero 23 de 2020).

28 Ibidem. 
accionante a través de un mecanismo que era integralmente, y desde todo punto de vista, inadecuado"29.

En vista de lo anterior, puede decirse que la Corte Constitucional basó su decisión en una mirada clásica respecto a la naturaleza y la estructura procesal constitucional del habeas corpus, con una consideración tradicionalista y conservadora. Incluso, se puede entrever de su decisión que basó su análisis en una visión paradigmática meramente "bienestarista" o de "antropocentrismo débil", sin permitirse innovar en esas categorías y abrir el espectro hacia un escenario más favorable para los animales.

En el salvamento de voto, la magistrada Fajardo es tajante en señalar:

En el caso del oso 'Chucho', la mayoría de la Sala Plena bloqueada en el laberinto formalista del derecho procesal no fue capaz como juez constitucional de avanzar en la protección animal, a pesar de que contaba con los elementos necesarios para hacerlo. En mi opinión, este era un momento histórico para consolidar estándares nacionales de protección, no solo bajo parámetros de sintiencia y de prohibición del maltrato injustificado, por lo cual promoví una deliberación amplia en este proceso. ${ }^{30}$

En últimas, la decisión mayoritaria de la Corte Constitucional plantea un retroceso en cuanto al paradigma de relacionamiento de los animales humanos con los no humanos. Fincando su decisión en un paradigma "bienestarista" o de "antropocentrismo débil", da prioridad a la conceptualización tradicionalista frente a la naturaleza, la estructura y la pertinencia de las acciones constitucionales, especialmente la del habeas corpus, al cual limitó única y exclusivamente para la protección del derecho a la libertad de las personas; y lleva el asunto a los ritualismos, aceptando incluso que actualmente pareciera existir un déficit en materia de acciones para la protección efectiva del bienestar de los animales en cautiverio. Veamos: "La Corte toma nota de que actualmente el ordenamiento jurídico no contempla un instrumento de naturaleza judicial diseñado específicamente para debatir sobre las condiciones de bienestar de los animales que, legalmente, se encuentran en cautiverio"31.

En otras palabras, se reconoce el valor ecosistémico y ambiental de los animales silvestres, pero desde el punto de vista de su valor intrínseco, pareciera tornarse nugatoria su protección, pues no existe una acción constitucional que permita su protección como especie individualmente considerada o no puede hacerse uso del habeas

\footnotetext{
29 Ibidem.

30 Ibidem.

31 Ibidem.
} 
corpus para solicitar su libertad al encontrarse en cautiverio, mucho menos cuando se "presume" que el cautiverio ha sido autorizado por la autoridad administrativa.

\section{LA ACCIÓN POPULAR COMO MECANISMO PARA LA PROTECCIÓN DE LA FAUNA SILVESTRE}

La acción popular fue consagrada en la Constitución Política como un instrumento de defensa de los derechos de "tercera generación" o, para ser exactos, aquellos que la Constitución en el capítulo 3 del título II denomina "derechos colectivos y del ambiente".

Dichos derechos colectivos y del ambiente se encuentran positivizados en los artículos 78 a 82 de la Constitución colombiana, así como en el artículo 88 y en el artículo 4 de la Ley 472 de 1998, reglamentaria de las acciones populares y de grupo; eso sí, con la salvedad de que no hay allí un catálogo taxativo de derechos, sino meramente enunciativo. Se pueden encontrar otros derechos colectivos en normas especiales e incluso en la jurisprudencia.

El artículo 88 constitucional puede verse como una de las novedades de la Carta magna al incluir el establecimiento de los derechos colectivos como una de las modalidades de los derechos humanos, así como la fijación de mecanismos para su protección, materializados en dos acciones: la popular, de carácter preventivo y protector, y la de grupo, de carácter reparatorio ${ }^{32}$.

A su vez, la Ley 1437 de 2011 (Código de Procedimiento Administrativo y de lo Contencioso Administrativo) consagró en el artículo 144 la posibilidad de que cualquier persona solicite la protección de los derechos e intereses colectivos cuando el agente vulnerador sea una entidad pública o un particular que ejerza funciones públicas o administrativas. Para esto, se podrán pedir medidas tendientes a evitar el daño contingente, a hacer cesar el peligro, la amenaza, la vulneración o el agravio, o a restituir las cosas a su estado anterior cuando fuere posible. Adicionalmente, dispuso que cuando la afectación o vulneración provenga de la actividad desplegada por una entidad pública, podrá demandarse su protección, incluso cuando la conducta vulneradora sea un acto administrativo o un contrato ${ }^{33}$.

Es importante señalar que la Ley 1437 de 2011 incorporó, como un medio de control jurisdiccional, la protección de derechos e intereses colectivos cuando quien

32 Manuel Fernando Quinche Ramírez, supra, nota 11.

33 Lucelly Rocío de las Mercedes Munar Castellanos y Luis Roberto Ortiz. DERECHO PROCesal administrativo y de lo contencioso administrativo. Temis. (2014). Pág. 194. 
vulnera o amenaza el derecho es una entidad pública, con lo cual, además de la reglamentación de la Ley 472 de 1998, se incluyeron ciertas aristas que más adelante referenciaremos para la acción popular.

Por contera, la acción popular, consagrada en el artículo 88 constitucional y reglamentada por la Ley 472 de 1998 y por la Ley 1437 de 2011, en principio constituye el camino procesal expedito para la protección de la fauna silvestre. Lo anterior encuentra respaldo en los literales a) y c) del artículo 4 de la Ley 472 de 1998, al señalar que son derechos e intereses colectivos, entre otros, los relacionados con: "a) El goce de un ambiente sano, de conformidad con lo establecido en la Constitución, la Ley y las disposiciones reglamentarias".

Debemos recordar que, de conformidad con el literal a) numeral 5 del artículo 3 del Decreto Ley 2811 de 1974 (Código Nacional de Recursos Naturales Renovables y de Protección al Medio Ambiente), la fauna hace parte de los recursos naturales renovables objeto de protección por ser parte del ambiente. Adicionalmente, el numeral c) de la Ley 472 de 1998 señala directamente como un derecho e interés colectivo:

La existencia del equilibrio ecológico y el manejo y aprovechamiento racional de los recursos naturales para garantizar su desarrollo sostenible, su conservación, restauración o sustitución. La conservación de las especies animales y vegetales, la protección de áreas de especial importancia ecológica, de los ecosistemas situados en las zonas fronterizas, así como los demás intereses de la comunidad relacionados con la preservación y restauración del medio ambiente.

Al respecto, el doctrinante y consejero de Estado Jaime Orlando Santofimio ha manifestado que:

En esta dirección en nuestro ordenamiento jurídico es competencia y deber primordial inaplazable de carácter constitucional a cargo de las autoridades ambientales, entre las cuales se encuentran las judiciales en ejercicio de la acción popular, el de la defensa del medio ambiente en cuanto principio edificante de nuestra estructura como Estado social de derecho. ${ }^{34}$

34 Jaime Orlando Santofimio Gamboa. ACCIONES POPULARES Y MEDIDAS CAUTELARES EN DEFENSA DE LOS DERECHOS E INTERESES COLECTIVOS: UN PASO EN LA CONSOLIDACIÓN DEL ESTADO SOCIAL DE DERECHO. Editorial Universidad Externado. (2010). Pág. 71 
Y enseña, sin dubitación alguna, que tanto en la instancia administrativa como en la judicial debe darse aplicación al principio de precaución:

No existe la menor duda jurídica de que constituye atribución clara, expresa y determinante para la defensa y protección del medio ambiente a cargo de las autoridades administrativas ambientales y judiciales, en especial en desarrollo de la acción popular, la de la utilización, cuando las circunstancias fácticas lo permitan y aconsejen, del principio de precaución como instrumento cautelar proporcional y adecuado al daño que se estima que puede sufrir el medio ambiente de no acudirse a este mecanismo, connatural a la perspectiva constitucional de los "deberes funcionales de protección" propios de la constitución ecológica y a la máxima in dubio pro ambiente..$^{35}$

Ahora bien, en la interposición de las acciones populares puede hacerse uso de las medidas cautelares, diseñadas a partir del artículo 230 de la Ley 1437 de 2011 y de los artículos 58 y siguientes de la Ley 472 de 1998, haciendo uso del principio de precaución. Esto en nuestro caso redundaría vehementemente en la posibilidad de exigirle al juez popular que decrete medidas cautelares tendientes a evitar la consumación de un daño frente a una especie animal silvestre. Así lo expresa Santofimio:

Las medidas de precaución o cautela serán proferidas por medio de acto administrativo debidamente motivado, en el cual la autoridad competente deberá ponderar su decisión con fundamento en los datos científicos existentes que aporten la información suficiente sobre el origen y los efectos de la concreción del riesgo potencial. Dicho principio no se reduce a la actividad administrativa, sino que debe inspirar la adopción de medidas cautelares dentro del proceso contencioso administrativo. ${ }^{36}$

Si nos adentramos en la protección de la fauna silvestre frente a una posible afectación, sobresale que el juez popular cuenta con múltiples posibilidades de protección, incluso cuando hay una amenaza de extinción. Por ejemplo, el artículo 129 del Decreto 1608 de 1978, compilado en el Decreto Único Reglamentario 1076 de 2015, establece la figura de la repoblación fáunica, la cual se define como: "[...] todo acto que conduzca a la reimplantación de poblaciones de especies o subespecies nativas 
de fauna silvestre en áreas en las cuales existen o existieron". Esta debe darse, entre otras cosas, para promover el incremento de poblaciones nativas de fauna silvestre, evitar su extinción y procurar su renovación secular.

Hasta aquí, vimos algunas posibilidades que tiene el juez popular cuando encuentre que una especie de fauna silvestre ha sido puesta en peligro o amenaza, incluso si dicha amenaza implica la posible desaparición o extinción. No obstante, no se encuentran muchos fallos en la jurisprudencia al respecto, en los que se proteja a la especie animal individualmente considerada, pues en nuestro territorio de momento hemos asumido un paradigma marcado por la incidencia o repercusión que exista frente al humano.

Al respecto, valga señalar una decisión trascendental que pone de relieve la dependencia de la protección animal de otras especialidades del derecho. Veamos: el Consejo de Estado, en fallo de acción popular del 26 de noviembre de 2013³7, profirió sentencia de segunda instancia en el marco de una acción popular elevada contra el Ministerio del Medio Ambiente y la Fundación Instituto de Inmunología de Colombia, a la cual se le otorgó una autorización para: "[...] la captura y estudio de investigación científica en diversidad biológica de primates en la cuenca del río Amazonas en el Trapecio Amazónico Colombiano"38, y en la cual el Consejo de Estado, entre otras cosas, manifestó que los animales podían ser sujetos de ciertos derechos, de la siguiente manera:

En el literal c) del artículo 4 de la Ley 472 de 1998, existe un reconocimiento expreso por parte del legislador de derechos directos y autónomos a favor de los animales y las especies vegetales en nuestro territorio nacional. Esa finalidad resulta incuestionable si se analiza la nueva normativa contenida en la Ley 1638 de 2013, que prohíbe el uso de animales silvestres en circos o espectáculos circenses, es decir, de nuevo el legislador les asignó derechos a seres vivos distintos al ser humano, de manera concreta, los derechos a no ser maltratados y a no vivir en condiciones precarias. ${ }^{39}$

Esta sentencia se considera de gran trascendencia. Sobre todo de una perspectiva de avanzada por parte del Consejo de Estado, pues a esa fecha no estaba

37 Consejo de Estado, Sala de lo Contencioso Administrativo. SENTENCIA 2011-00227 DE 2013. (M.P. Enrique Gil Botero; noviembre 26 de 2013).

38 Ibidem.

39 Ibidem. 
vigente la Ley 1774 de 2016, la cual condena el maltrato animal en Colombia y eleva a la categoría de ser sintiente a los animales ${ }^{40}$. De igual importancia resulta la cita que en dicha providencia se hace respecto a una sentencia del año 2012, en la que el Consejo de Estado puntualizó:

A contrario sensu, el principio de dignidad implícito en estos seres vivos
haría que toda institución jurídica -incluida la responsabilidad extracon-
tractual civil o del Estado- tuviera en cuenta esta condición, que serían
fines en sí mismos, y que, por lo tanto, son susceptibles de ser titulares de
derechos (v.gr. el derecho a no ser maltratado, el derecho a una muerte
digna sin sufrimiento, entre otros). ${ }^{41}$

Es de aclarar que, tal como sucedió en el caso del oso 'Chucho', por efectos de la revisión de sentencias (incluso de segunda instancia) a través de la acción de tutela, cuando hay "vulneración de derechos fundamentales" y se alegan defectos procedimentales y sustantivos contra las sentencias, la Fundación Instituto de Inmunología de Colombia interpuso acción de tutela contra la decisión proferida el 26 de noviembre de 2013 por la Sección Tercera, subsección "c", de la Sala Contencioso Administrativa del Consejo de Estado en fallo de acción popular, alegando vulneración al debido proceso, a la igualdad y al buen nombre. Por eso, la Sección Cuarta de la Sala Contencioso Administrativa del Consejo de Estado profirió fallo de acción de tutela en el que, al estudiar el defecto procedimental y sustantivo, determinó que los animales no son sujetos autónomos de derechos y consideró que, por esa razón, los científicos colombianos sí podían utilizar monos en las investigaciones para la cura de enfermedades tropicales.

A su vez, argumentó que es desproporcionado que la protección de animales silvestres se anteponga al objetivo de combatir afecciones que causan millones de muertes de seres humanos, especialmente niños ${ }^{42}$. Es importante mencionar que no hubo pronunciamiento de fondo en segunda instancia por parte de la Sección Quinta de la Sala Contencioso Administrativa del Consejo de Estado, pues consideró que el recurso de impugnación contra el fallo de tutela se había interpuesto de forma extemporánea.

40 Luz Marcela Pérez Arias y Milton Dubán Monsalve Mantilla, supra, nota 8.

41 Consejo de Estado, Sala de lo Contencioso Administrativo. SENTENCIA 1999-0909 DE 2012. (M.P. Enrique Gil Botero; mayo 23 de 2012).

42 Consejo de Estado, Sala de lo Contencioso Administrativo. SENTENCIA 2014-00723 DE 2014. (M.P. Carmen Teresa Ortiz de Rodríguez; diciembre 12 de 2014). 
Aquí vemos otro ejemplo en el que claramente las consideraciones y la construcción epistemológica de otras especialidades del derecho terminan anteponiéndose a la protección real y verdadera de los animales, y, aunque la acción popular se encuentre consagrada para la protección de ese derecho colectivo, la visión tradicionalista y conservadora termina imponiéndose y haciendo nugatoria la pretensión de salvaguarda de los animales.

\section{CONCLUSIONES}

De conformidad con el reciente fallo de la Corte Constitucional en Sentencia de Unificación 016 de enero de 2020, el habeas corpus solo es procedente para la protección del derecho fundamental a la libertad de las personas, entendiendo el concepto de persona en su visión más tradicional y conservadora. Por tanto, el habeas corpus se encuentra dispuesto única y exclusivamente en favor de los humanos, no siendo posible su utilización en el caso de los animales. A tal conclusión llega la Corte tras una visión tradicionalista, conservadora y sustentada en el paradigma exclusivamente "bienestarista" o de "antropocentrismo débil" frente a los animales.

La protección y conservación de los animales constituye un derecho colectivo de conformidad con los artículos 8, 79, 80, 88 y 95-8 de la Constitución Política, el artículo 3 del Código Nacional de Recursos Naturales Renovables y de Protección al Medio Ambiente (Decreto Ley 2811 de 1974), y los literales a) y c) del artículo 4 de la Ley 472 de 1998. Por ende, puede solicitarse la protección y conservación de los animales a través de la acción popular, pero bajo el entendido de los animales como parte de una especie y no vistos desde su individualidad o su "valor intrínseco".

Debe crearse una nueva especialidad del derecho en Colombia, denominada "derecho animal", con un objeto de estudio independiente y autónomo, que logre construir instituciones, mecanismos, acciones y procedimientos propios que realmente centren su margen de acción en la protección, conservación y garantía de las especies animales como especies y como individuos en su consideración "intrínseca", al margen de las formalidades y discusiones epistemológicas sobre las que se han construido otras especialidades del derecho, como las del derecho procesal constitucional. 


\section{REFERENCIAS}

Congreso de la República. Ley 99 de 1993. Por la cual se crea el Ministerio del Medio Ambiente, se reordena el Sector Público encargado de la gestión y conservación del medio ambiente y los recursos naturales renovables, se organiza el Sistema Nacional Ambiental, sinA, y se dictan otras disposiciones. Diciembre 22 de 1993. Do N.º 41.146.

Congreso de la República. Ley 1638 de 2013. Por medio de la cual se prohíbe el uso de animales silvestres, ya sean nativos o exóticos, en circos fijos e itinerantes. Junio 27 de 2013. DO N.º 48.834 .

Congreso de la República. Ley 1774 de 2016. Por medio de la cual se modifican el Código Civil, la Ley 84 de 1989, el Código Penal, el Código de Procedimiento Penal y se dictan otras disposiciones. Enero 6 de 2016. Do N. ${ }^{\circ} 39.120$.

Congreso de la República. Ley 1801 de 2016. Por la cual se expide el Código Nacional de Seguridad y Convivencia Ciudadana. Julio 29 de 2016. Do N. 49.949.

Consejo de Estado, Sala de lo Contencioso Administrativo. SenTENCIA 1999-0909 DE 2012. (M.P. Enrique Gil Botero; mayo 23 de 2012).

Consejo de Estado, Sala de lo Contencioso Administrativo. Sentencia 2011-00227 DE 2013. (M.P. Enrique Gil Botero; noviembre 26 de 2013).

Consejo de Estado, Sala de lo Contencioso Administrativo. SentenCIA 2014-00723 DE 2014. (M.P. Carmen Teresa Ortiz de Rodríguez; diciembre 12 de 2014).

Corte Constitucional de Colombia. SentenciA SU-016 DE 2020. (M.P. Luis Guillermo Guerrero Pérez; enero 23 de 2020).

Diego Lopéz Medina. El CAMBIO dogmÁTICO-JURíDICO COMO RESPUESTA AL CAMBIO SOCIAL: LA LABOR DEL CONSEJO DE ESTADO Y DE LA CORTE CONSTITUCIONAL EN LA RECONSIDERACIÓN DEL ESTATUTO JURÍDICO DE LOS ANIMALES EN COLOMBIA. Editorial Universidad Externado. (2015).

Jaime Orlando Santofimio Gamboa. AccIONES POPULARES Y MEDIDAS CAUTELARES EN DEFENSA DE LOS DERECHOS E INTERESES COLECTIVOS: UN PASO EN LA CONSOLIDACIÓN DEL ESTADO SOCIAL DE DERECHO. Editorial Universidad Externado. (2010).

Juan Carlos Guayacán. La selección de sentencias para la unificación de la jurisprudencia. Tres historias paralelas entre la Corte Constitucional, el Consejo de Estado y la Sala de Casación 
Civil de la Corte Suprema de Justicia. Revista de Derecho Privado 19. Diciembre de 2020. Pág. 57-79.

Lucelly Rocío de las Mercedes Munar Castellanos y Luis Roberto Ortiz. DERECHO PROCESAL ADMINISTRATIVO Y DE LO CONTENCIOSO ADMINISTRATIVO. Temis. (2014).

Luz Marcela Pérez Arias y Milton Dubán Monsalve Mantilla. Maltrato animal en Colombia: protección penal y contravencional en favor de los animales. DIXI 32. 2020. Pág. 1-16. Disponible en: https://doi.org/10.16925/2357-5891.2020.02.07

Manuel Fernando Quinche Ramírez. DERECHO PROCESAL CONSTITUCIONAL COLOMBIANO. ACCIONES Y PROCESOS. Ediciones Doctrina y Ley. (2015).

María Cristina Patiño González. El habeas corpus. Revista DeRECHO DEL ESTADo 8. Junio de 2000. Pág. 127-158.

Martha Nussbaum. LAS FRONTERAS DE LA JUSTICIA: CONSIDERACIONES SOBRE LA EXCLUSIÓN. PaidóS. (2006).

Óscar Darío Amaya Navas. LA CONSTITUCión ECOLÓGICA DE COLOMBIA. Editorial Universidad Externado de Colombia. (2010).

Pablo Dermizaky Peredo. El derecho proceso constitucional. ReVISTA BOLIVIANA DE DERECHO 4. 2007. Pág. 1-20.

Presidencia de la República. Decreto Ley 2811 de 1974. Por el cual se dicta el Código Nacional de Recursos Naturales Renovables y de Protección al Medio Ambiente Diciembre 18 de 2019. DO N. ${ }^{\circ} 34.243$. 